\section{Pesquisa social em ambientes digitais em tempos de COVID-19: notas teórico-metodológicas}

\author{
Social research in digital environments in \\ COVID-19 times: theoretical and \\ methodological notes
}

Investigación social en ambientes digitales en tiempos de la COVID-19: notas teórico-metodológicas
Suely Deslandes 1

Tiago Coutinho 2

\section{Resumo}

A pandemia de COVID-19e as medidas sanitárias de distanciamento social trouxeram impasses para a pesquisa social e o seu futuro. A pesquisa em ambientes digitais já estava em franca expansão, mas neste momento de suspensão de atividades presenciais, torna-se uma alternativa para viabilizar a continuidade dos estudos. Compreendê-la melhor se torna uma necessidade epistemológica e metodológica para todos os pesquisadores. Assim, o objetivo desse ensaio é propor algumas considerações teórico-metodológicas sobre a pesquisa qualitativa nos diferentes ambientes digitais formados pela Internet 2.0. Pontuamos alguns aspectos e tensões introdutórias que consideramos estratégicas para os que vão começar seu trabalho nas redes de sociabilidade sustentadas pela Internet. Organizamos o artigo a partir dos seguintes tópicos: (1) a sociabilidade digital; (2) o "ambiente digital" e o borramento de fronteiras entre real-virtual; (3) a redefinição do significado de "campo" na ambiência digital; (4) os diferentes usos culturais das plataformas digitais; (5) as plataformas como produtoras de gêneros discursivos; (6) a produção e extração de acervos. O ensaio procura demonstrar que a pesquisa nas ambiências digitais descortina um campo exponencial de possibilidades, seja para explorar as formas que essa socialidade assume em nossos cotidianos, para modular nossas (inter) subjetividades, como permite a produção de narrativas e performances identitárias, associações para propósitos diversos, entre tantas outras possibilidades. Todavia, demanda uma compreensão da ação social a partir da sinergia dos contextos sócio-técnico-culturais que a estruturam.

COVID-19; Internet; Mídias Sociais; Pesquisa Qualitativa; Metodologia

\author{
Correspondência \\ S. Deslandes \\ Departamento de Ensino, Instituto Nacional de Saúde da \\ Mulher, da Criança e do Adolescente, Fundação Oswaldo Cruz. \\ Av. Rui Barbosa 716, Rio de Janeiro, RJ 22250-020, Brasil. \\ desland@iff.fiocruz.br \\ 1 Instituto Nacional de Saúde da Mulher, da Criança e do \\ Adolescente, Fundação Oswaldo Cruz, Rio de Janeiro, Brasil. \\ 2 Escola Nacional de Saúde Pública Sergio Arouca, Fundação \\ Oswaldo Cruz, Rio de Janeiro, Brasil.
}


A pandemia da COVID-19 causada pelo novo coronavírus (SARS-CoV-2) e as medidas sanitárias para seu enfrentamento trouxeram questionamentos e dilemas para a pesquisa social e o seu futuro. As pesquisas dedicadas à produção de um conhecimento que se elabora com base na compreensão pela interpretação da ação dos indivíduos e grupos 1, e que usualmente são realizadas valendo-se da convivência cotidiana e de trocas conversacionais presenciais com os sujeitos estão suspensas. Os estudos que envolvem a construção de um trabalho de campo, os de cunho etnográfico ou observacional, que planejam entrevistas e práticas grupais estão sendo agora revisados dadas as condições impostas pela pandemia 2. E ao que parece, não se trata apenas de esperar alguns meses para que a "normalidade" seja restaurada. As fases de readaptação do convívio social poderão ser longas e mesmo sofrer retrocessos, caso novas ondas de contágio sejam identificadas ${ }^{3}$.

A partir das recomendações da Organização Mundial da Saúde de distanciamento social, a comunicação mediada por computador assume importância fundamental como a forma estratégica de gerir o cotidiano ${ }^{4}$. Mesmo antes, a partir do que se denominou de Internet 2.0, com a criação de plataformas capazes de propiciar interatividade entre internautas, a Internet gradativamente demarcou novos alicerces culturais e de socialidade 5,6,7.

Se, a partir de 2010 observou-se a consolidação de novos campos de estudo, como Sociologia Digital 8,9 e Antropologia Digital 10,11, as interdições de contato presencial durante e pós-pandemia podem fazer com que as metodologias digitais se tornem uma necessidade para a pesquisa social. É importante lembrar que esse já é um campo em plena expansão na área da saúde, em que se multiplicam estudos sobre as mudanças na relação médico/paciente após a Internet 2.0, consumo de medicamentos e autocuidados, avaliação das informações em saúde disseminadas online, associativismos, identidades construídas com base nas experiências de adoecimento, prevenção e diversos outros temas que proliferam com a diversificação da interação online 12,13,14,15,16.

Se a pesquisa em ambientes digitais se restringia a um grupo de estudos específicos no âmbito da pesquisa social, neste momento, compreendê-la melhor se torna uma necessidade epistemológica e metodológica para todos os pesquisadores. Certamente, não se trata de uma solução indistinta a todas as pesquisas, pois tais decisões envolvem uma leitura de coerência aos objetivos do estudo, podendo indicar a necessidade de dinâmicas investigativas que articulem os espaços online e offline, buscando captar as diferentes performances e interações nestes espaços e o modo como as tecnologias interatuam nas práticas sociais.

Assim, o objetivo deste ensaio é propor algumas considerações teórico-metodológicas sobre a pesquisa qualitativa nos diferentes ambientes digitais formados pela Internet 2.0. Pontuamos alguns aspectos e tensões introdutórias que consideramos estratégicas para os que vão começar a lidar com os conjuntos de textos (em sua concepção ampla, portanto, incluindo textos, imagens, sons e outras mídias que constituam expressões socioculturais) produzidos nas redes de socialidade sustentadas pela Internet. Organizamos o artigo com base nos seguintes tópicos: (1) a socialidade digital; (2) o "ambiente digital" e o borramento de fronteiras entre real/virtual; (3) a redefinição do significado de "campo" na ambiência digital; (4) os diferentes usos culturais das plataformas digitais; (5) as plataformas como produtoras de gêneros discursivos; (6) a produção e extração de acervos. Nosso intuito não é abordar exaustivamente esses temas, mas produzir alguns questionamentos sobre a natureza sui generis desse campo de interações sociais, num contexto mediado e induzido por plataformas digitais.

\section{A socialidade digital}

A socialidade diz respeito a novos dispositivos da vida cotidiana comum que não passam pelos parâmetros de sociabilidade ocidental (ancorada nos pressupostos inatos do individualismo, nas formas morais e de sociação pelas quais os indivíduos se agrupam), mas que valorizam os arranjos afetivos e intersubjetivos que permitem pensar esta potência gregária 17,18. Assim, a socialidade assumirá novos contornos a partir do marco tecnológico definido como Internet 2.0. A partir dos anos 2010, a fibra ótica permitiu que uma imensa quantidade de dados fosse trocada entre os usuários, resultando em duas importantes mudanças: a total mobilidade por meio dos dispositivos móveis e, principalmente, a produção de conteúdo por não especialistas, pois a partir da criação de interfaces interativas e de diversos tutoriais qualquer usuário poderia criá-lo e inseri-lo em plataformas colaborativas 19. 
$\mathrm{O}$ advento e barateamento das tecnologias que dão acesso às plataformas provocaram uma nova onda de conteúdos referentes ao banal e ao cotidiano que voltaram a ganhar notoriedade no final do século XX 20 . Ainda que muitos conteúdos institucionais, acadêmicos, empresarias e de saúde ganhassem importância nessa nova fase da Internet, observou-se que os conteúdos ligados à intimidade do cotidiano obtiveram maior notoriedade e visibilidade. Aquilo que em um momento anterior era conhecido como espectador, agora tem a possibilidade de ser protagonista de sua própria vida-vídeoblog-live, um verdadeiro espetáculo de si mesmo 21.

A socialidade vai ser assim redefinida com base nas agências humanas e cotidianas de apropriações e usos dessas novas tecnologia digitais. Assumindo uma dinâmica fluída, provisória e gregária por focos de interesses vinculados a afetos, sensibilidades e erotismo 18. Como explicitam Horst \& Miller 11 e Miller \& Slater 22, a Internet faz parte de uma cultura material que potencializa formas culturais de relacionamentos entre as pessoas. Baseando-se em seus referentes culturais, as pessoas criam formas de se relacionar com cada uma dessas mídias, acionando valores, estéticas e moralidades de seu grupo social.

Com base em plataformas como Instagram, Twitter, Facebook, Tinder etc., observa-se que as redes de interações digitais definem e dependem da forma que o "eu" irá se apresentar para os "outros", que por sua vez se presentificam de diversas maneiras no discurso construído por este "eu" digital. Assim, o "outro" apresenta-se como uma audiência oculta que constantemente medeia a forma de apresentação de si nas redes sociais. Não à toa, os estudos de Goffman retornam com força 23,24. Na pretensão de ser amado, apreciado e aplaudido, os indivíduos estariam submetidos ao que Sibilia 21 chamou de "tiranias da visibilidade", tendo de estilizar e cultivar suas imagens aos moldes de personagens da mídia audiovisual. A hiperexposição torna-se assim uma característica intrínseca desta socialidade digital, numa projeção palinóptica, em que muitos vigiam muitos 25 .

A socialidade digital se realiza por diversas linguagens (verbal, corporal, algorítmica, multimídia) que são apreendidas pelo corpo, por meio da forma com que o indivíduo performaticamente se apresenta para o outro. Importa notar que essas plataformas-empresas onde acontecem as interações estão voltadas para a obtenção de lucro, ou seja, visam à máxima disseminação de seus conteúdos e proposições ${ }^{19}$. Assim, a hiperexposição será estimulada no anseio capitalista de diversificar a forma de marketing e poder de persuasão de seus consumidores 26 .

A hiperexposição, que por um lado permite o desvendamento das esferas íntimas, sendo material potencial para a pesquisa social, desafia o pesquisador no campo ético, por exemplo. Proteger os sujeitos da pesquisa quando há tamanha exposição é ainda mais necessário. Assim, há que levar em conta o efeito "plateia" em muitas das comunicações que circulam na Internet. Demanda ainda desvelar as versões e narrativas com base no contexto midiático e relacional onde foi produzido e de suas múltiplas intenções para audiências diversas 27.

\section{Os ambientes digitais: borramento de fronteiras entre real/virtual e a pesquisa mediada por tecnologia}

Ainda que seja possível "habitar e viver vidas alternativas, específicas, a partir da tecnologia digital, por meio de avatares em um ambiente imersivo" 28 (p. 191) com a chegada da Internet 2.0, percebeu-se que ao invés da consolidação de um mundo paralelo àquele concebido como real, o que houve foi um movimento de digitalização do cotidiano. Os smartphones, tablets e relógios incorporaram os aplicativos, ou seja, algoritmos digitais que presentificam as diferentes plataformas nos dispositivos móveis. Assim a refeição pedida em um aplicativo de alimentação, o "date" marcado por um aplicativo de encontro ou a consulta do tráfego de uma cidade em um aplicativo de trânsito são exemplos de que a realidade está se digitalizando. Por esse motivo, o termo "digital" irá substituir o termo "virtual" para designar os ambientes disponibilizados pela Internet 2.0. Essa noção de digital dialoga com a noção de virtualidade trabalhada por Lévy 29, que define esta instância como sendo "toda entidade 'desterritorializada", capaz de gerar diversas manifestações concretas em diferentes momentos e locais determinados, sem contudo estar ela mesma presa a um lugar ou tempo em particular" 29 (p. 11). Esses modos de ser não correspondem a mundos opostos, mas complementares. 
A tecnologia foi definitivamente incorporada e corporificada em nossas vidas cotidianas, como sintetiza Cristine Hine 30, ela é embedded, embodied, and everyday. Assim, qualquer binarismo entre real/ virtual, digital/analógico perde seu sentido. Nesse ponto, é importante mencionar que a TAR (Teoria Ator-Rede), desenvolvida por Latour et al. 31 ao longo de inúmeras publicações, tratou a tecnologia como um ator dotado de agência que passa a ter protagonismo na Teoria Social. As plataformas e ambientes digitais passam então a ser estudados como atores não humanos. A própria noção de "ator" se transforma com essa teoria que passa a prestar mais atenção nas associações em redes que fazem os actantes humanos e não humanos do que em seus atributos intrínsecos. O termo "actante" vai enfatizar as alianças, fluxos e mediações entre humanos e tecnologias, ou seja, o actante é o mediador, o articulador da rede nele mesmo e fora dele em associação com outros. Essa interação aberta e imprevisível é capaz de produzir conhecimentos e efeitos no coletivo.

A chegada da Internet 2.0 também consolida uma mudança de paradigma em relação ao papel da tecnologia nas pesquisas sociais. Se em um primeiro momento essa era concebida meramente como um meio auxiliar para registrar uma determinada forma de socialidade e suas dinâmicas, atualmente a tecnologia é o próprio espaço de interação e agregação dos sujeitos. Contudo, a relevância da tecnologia como propiciadora da produção de dados de campo não é nova. Em sua célebre introdução da obra Argonautas do Pacífico Ocidental, Malinowski 32 destacou a importância da tecnologia para retratar uma cultura respeitando os padrões científicos de sua época. Além do diário de campo e da observação participante, Malinowski sugeriu que o pesquisador deveria utilizar todos os meios tecnológicos disponíveis (na sua época o gravador de voz e a máquina fotográfica) para retratar aquilo que chamou de "imponderáveis da vida cotidiana".

Com a "digitalização da vida cotidiana", observa-se que a tecnologia aplicada à pesquisa social não funciona meramente como ferramenta auxiliar para a captação de dados. Essa torna-se o meio pelo qual a socialidade dos sujeitos de pesquisa é colocada em prática. Pode-se dizer que o mundo digital engloba todos os campos de interação da vida social, daqueles mais íntimos e privados (como relacionamentos afetivo-sexuais ou de controle de ciclos corporais como a menstruação) até os de esfera macro, como grandes movimentações financeiras transnacionais.

Essa mudança de paradigma em relação ao papel da tecnologia nas pesquisas sociais tem como principal desdobramento prático a tomada de consciência por parte do pesquisador que a tecnologia tem esse duplo caráter: se por um lado ela é o lócus privilegiado onde os interlocutores desenvolvem suas interações, por outro ela auxilia na extração, mensuração e análise dos dados. Assim, todas as etapas da pesquisa serão mediadas pelo mundo digital, desde sua análise exploratória de reconhecimento do campo até a escrita do texto final, e neste percurso haverá pouca distinção entre o offline e o online.

Do ponto de vista da sociologia, pode-se afirmar que o mundo digital é um fato social total tal como preconizara Mauss 33 (p. 21), ou seja, "é uma atividade que tem implicações em toda a sociedade, nas esferas econômicas, jurídicas, políticas e religiosas", de tal modo que "informa e organiza as instituições e práticas aparentemente bastante distintas".

\section{Os diferentes usos socioantropológicos das plataformas}

De acordo com Silveira 26, o mundo digital é atravessado por algoritmos, com enorme sucesso e eficácia em nossas relações sociais, econômicas e políticas. Essas sequências finitas de programação que visam a dar solução para um determinado tipo de problema ou busca a partir de entradas anteriores são apresentadas pelo mercado como algo que não precisamos saber como funcionam, desde que cumpram sua finalidade. Algoritmos são considerados ferramentas que além de auxiliar nas tarefas do cotidiano, direcionariam estas atividades de acordo com o interesse econômico. Eles nos ajudam a encontrar amigos de infância no Facebook, auxiliam na venda de produtos no Instagram com base na sua rede de amizades, e até mesmo incutem gradativamente ideologias políticas por meio de sequências de mensagens que sejam compatíveis ao seu histórico de buscas; em suma, as possibilidades são tantas e variam de acordo às associações com o ambiente informacional.

Os algoritmos podem ser vistos como produtores de campos de interação entre indivíduos com regras e condutas específicas que se materializam nas plataformas que atraem milhões de usuários pelo mundo. Essa variedade de opções de interações algorítmicas entre as pessoas e a forma com 
que os indivíduos realizam suas escolhas nesse ambiente foi o foco de uma pesquisa coordenada por Madianou \& Miller 34 sobre o uso sociocultural das plataformas digitais. O projeto de pesquisa Why We Post examinou o impacto global das novas mídias sociais. O estudo baseou-se em dados etnográficos coletados ao longo de 15 meses na China, Índia, Turquia, Itália, Reino Unido, Trinidad e Tobago, Chile e Brasil. Destacou os diferentes usos culturais das plataformas, como por exemplo, o papel social do "selfie", os famosos autorretratos da era digital, nos diferentes países estudados.

Um dos conceitos norteadores do projeto foi o de polymedia, uma ferramenta conceitual que expõe as conectividades internas em relação às comunicações pessoais externas. Os autores dizem que não podemos tratar cada nova mídia que surge no mercado de forma independente, uma vez que estas fazem parte de uma ecologia mais ampla de diferentes mídias ${ }^{34}$. Por exemplo, usar o email pode ser uma opção mais socialmente aplicável do que mensagens de texto no celular ou até mesmo a utilização de mensagens instantâneas disponíveis em site de rede social; realizar um comentário na postagem de um amigo às vezes é mais socialmente adequado do que postar diretamente em seu mural. Assim os autores conceituam polymedia como o ambiente que emerge da ampla gama de oportunidades comunicativas que funciona como uma "estrutura integrada" dentro da qual cada meio individual é definido em termos relacionais no contexto de todas as outras mídias. Dessa forma, a navegação no ambiente da polymedia se torna inextricavelmente ligada às maneiras pelas quais as relações interpessoais são promulgadas e experimentadas. Como consequência, a polymedia ajuda a ressocializar a tecnologia, uma vez que a responsabilidade da escolha muda de preocupações técnicas e econômicas para morais, sociais e emocionais. Ao contrário de uma leitura de determinismo tecnológico, "a situação da polymídia é aquela em que a tecnologia é mediada pelo relacionamento interpessoal e vice-versa" 34 (p. 172).

Assim, o pesquisador que realiza sua investigação em ambiência digital deve ficar atento ao significado e ao uso que cada pessoa atribui a um determinado aplicativo ou plataforma como resultado de um conjunto de relações e teias de significados de uma dada cultura. De qualquer maneira, vale o questionamento constante do pesquisador sobre os modos de dizer, pensar e agir expressos nas interações online em interseção com a modelagem e indução de comportamentos que as plataformas digitais produzem com base em seus interesses comerciais.

\section{Plataformas e gêneros discursivos}

Partindo desse ponto de vista socioantropológico da ação de códigos matemáticos, consideramos que cada plataforma digital convoca aos seus usuários certa forma de compor sua produção discursiva, certo repertório mais ou menos estável de temas e um estilo próprio, envolvendo o gradativo domínio dos recursos lexicais e fraseológicos aprendidos como apropriados para aquela comunicação, bem como uma forma de estruturar os enunciados. Dessa forma, podemos reconhecer que as plataformas constroem gêneros discursivos próprios, tal como conceitua Bakhtin 35.

De acordo com Maingueneau 36, a web transforma as condições de comunicação, altera a maneira pela qual consideramos o gênero e a noção mesma de textualidade. $\mathrm{O}$ autor sugere que a Internet tem uma textualidade "navegante" solidária a novas formas de leituras baseadas em hipertextos ou hiperdocumento. Não se trata propriamente de falar de um texto, de uma ordem superior, mas de um sistema contingente construído pelo internauta: "O hipertexto (ou hiperdocumento) é um conjunto de textos, imagens e sons - nódulos - conectados por links eletrônicos de modo a formar um sistema cuja existência é contingente além do computador" 36 (p. 155).

Dessa forma, ao pesquisar a produção discursiva produzida nas redes sociais digitais, um bom começo é questionar quais temas mais frequentes são abordados. Quais comportamentos são modelados por aquela plataforma por meio da conformação das funções interacionais oferecidas? Qual estilo gramatical, fraseológico ali se imprime? Há diferença das expressões empregadas por pessoas de distintos grupos sociais e gerações? Qual intertextualidade aquela comunicação apresenta? Dialoga com quais outras linguagens e textos?

Os lemas de cada plataforma, por exemplo, parecem sugerir um desempenho discursivo aos seus partícipes. O Facebook quer que você diga "o que você está pensando", numa espiral de testemunhos que almejam acumular a importante moeda de reconhecimento, que vai de sua expressão mais efêmera (os likes) aos comentários e até os compartilhamentos nas "comunidades" dos usuários. O Twitter 
deseja ser um sensor das "tendências" da sociedade (política, comportamento, moda etc.), uma janela para que se "veja o que está acontecendo no mundo nesse momento". Inicialmente associado como um espaço para as "celebridades" se conectarem aos seus fãs, popularizou seu perfil, mas ainda hoje marca a atuação intensa de figuras públicas e daqueles que buscam notoriedade. $\mathrm{Na}$ descrição de adesão, a pergunta que é feita ao novo usuário é: “o que torna você especial?”. Os participantes podem ser seguidos ou seguidores, numa clara alusão de criação de séquitos. A popularidade expressa pelo número de seguidores dará o status de influenciador digital a quem possui uma robusta "cartela de clientes". O YouTube, com o lema "transmita você mesmo", convida seu usuário a criar e publicar vídeos os mais variados. Desde os tutorais do "como fazer", que inauguraram esse espaço interacional, às mais variadas expressões artísticas, jornalísticas, educacionais, bem como de performances individuais. Cada um almeja ter seu canal e agremiar muitos inscritos. A plataforma inclusive disponibiliza um manual para dar dicas técnicas de como tornar seu canal popular. O Instagram, por sua vez, tem como lema "capturando e compartilhando os momentos do mundo". Com forte apelo visual, impregnado pela sua origem de espaço de edição e compartilhamento de fotos, passa a permitir a produção de textos, postagem de vídeos, narrativas e expressão de comunidades. Como plataforma mais recente, vai rapidamente incorporando as funções e ferramentas das plataformas mais antigas.

Entendemos que o pesquisador pode tratar as plataformas como contexto enunciativo onde acontecem as interações e práticas analisadas, levando em conta o gênero discursivo que delimita. Como define van Dijck 19, as plataformas são estruturas performativas, não funcionam como meras mediadoras da comunicação, mas conformam comportamentos sociais. Assim, conhecer a história de criação do site/aplicativo e os seus intentos corporativos parece útil para análise. Quais funções, ferramentas comunicacionais são oferecidas e o que elas sugerem aos usuários? Como tais ferramentas interferem nas interações entre os participantes? Saber qual geração utiliza aquele site/aplicativo, se sua forma de uso varia entre homens e mulheres, e em diferentes culturas pode também ser relevante para compreender os discursos ali produzidos.

\section{A redefinição do significado de "campo" na ambiência digital}

As pesquisas que envolvem um "trabalho de campo" comungam da herança etnográfica sobre a produção de conhecimentos com base na participação no cotidiano de uma determinada comunidade, povo, grupo social ou instituição. O "estar" no campo até então envolvia a ideia de uma certa territorialidade geograficamente existente. No campo, o pesquisador emprestaria seu próprio corpo e subjetividade a uma imersão no mundo do vivido, compartilhando com os sujeitos de pesquisa as situações baseando-se em um lugar epistemicamente diferenciado ${ }^{37}$. Na pesquisa digital esses termos de ancoragem da produção do conhecimento (território, comunidade/grupo, corpo) serão diferentes. Embora em distintas plataformas se estimule a participação em "comunidades", na socialidade digital tal sentido é muito peculiar e diferente das acepções originalmente idealizadas de Tönnies 38 . As comunidades da Internet não correspondem à ideia de um passado em comum, ao pertencimento à família, aldeia, ou seja, ao lócus definido pela tradição e solidariedade orgânica, como previra Durkheim. Os agrupamentos que surgem nas redes sociais e mantêm laços entre si não têm uma base territorial, mas um "ciber-lugar", simbolicamente definido em torno de um tema interesse, que pode ser fugidio ou mais permanente, e em torno do qual uma parcela significativa da interatividade ocorre e se mantém 20,39. O sentido de um território geograficamente delimitado se perde nas fronteiras online/offline, são fluídos e dinâmicos. Um doente crônico, por exemplo, pode circular por várias plataformas e comunidades, assumindo em cada, uma narrativa diferente. Dessa maneira, o pesquisador é desafiado a compreender esses diferentes fluxos e trânsitos, bem como as variações interacionais que se apresentam em cada ambiência online. Assim, o "campo" da pesquisa digital é mais um fluxo do que um "lugar", uma rede de conexões que entrecruzam interações cotidianas distintas, ancoradas em muitas plataformas e ambiências tecnológicas, e o mundo offline. A ideia de campo sem território ou lugar não é uma novidade na tradição etnográfica, como lembra Hine 30 , esse debate já aparecia nos estudos sobre refugiados e migrantes, todavia, nos estudos digitais a concepção de campo multilocalizado ganha novo sentido, explorando suas dimensões de conexão e mobilidade 40 . 
Markham 41 discute que os contextos mediados pela Internet podem assumir diferentes significados para o pesquisador, sendo interpretado como: (1) um meio para conectividade em rede; (2) local ou mundo virtual; e (3) uma maneira de ser, uma totalidade. A depender desse posicionamento heurístico não excludente, o pesquisador poderá adotar posturas distintas em seu trabalho de campo. $\mathrm{A}$ primeira perspectiva dará atenção à socialidade digital entendida "como microssistemas tecnoculturais de significado se fundem através da convergência de muitos elementos, incluindo conteúdo, infra-estruturas tecnológicas e padrões de uso" 41 (p. 1130). Interessa ao pesquisador as práticas individuais e de grupo, situadas culturalmente, e como estas são vivenciadas pela Internet, nessa "cultura da conectividade". A própria ideia original de "campo" é ressignificada para "rede", onde os interesses do estudo se localizam. A segunda leitura entende a Internet como um ambiente imersivo, multiuso e performativo. Na terceira perspectiva, a Internet é onde a vida do dia a dia acontece, reforçada de corporalidade e seus sentidos e embebida das regras da cultura, enfim, uma tecnologia que medeia de forma cotidiana a vida 10 .

Se o trabalho de campo tem como propósito pragmático a produção de dados, demarcar uma empiria para a reflexão teórica, como será a agência desse pesquisador na esfera digital? As distintas abordagens qualitativas têm como importante assertiva em comum que seus dados não têm uma materialidade imanente, ao contrário, só existem porque são construídos, ou seja, são coproduzidos nas singulares interações entre sujeitos envolvidos na pesquisa 1,32,42. Mesmo os estudos que se baseiam em documentos preexistentes, em bases materiais que testemunham direta ou indiretamente práticas sociais, é importante lembrar que também esse tipo de acervo foi coproduzido baseando-se em sucessivas decisões arbitrárias de quem o produziu e o compilou. Todavia, o trabalho de campo, seja de base observacional ou não, não tem como propósito a compilação de dados per si, mas produzir por meio desse conjunto de materiais uma reflexão de cunho interpretativo. O desafio posto é o produzir um trabalho intelectual valendo-se desse acervo, que possibilite uma "descrição densa" das redes de significado que traduzem uma cultura ou uma prática social 42 . E tal tarefa não é diferente na pesquisa digital.

Da mesma forma que o pretenso "controle das observações" do pesquisador é diferente na pesquisa em ambiência digital. A mudança de expressões corporais e faciais, os subtons vocais, as "piscadelas" do querer significar algo diferente do que se disse nem sempre serão notados. Tampouco as ações realizadas (postagens, comentários online) serão compreendidas sem acessar os contextos interacionais que dão inteligibilidade às reações geradas 30 .

Certamente, mesmo num contexto observacional presencial, o pesquisador nunca dá conta de todas as relações e interações, mas elege eixos centrais por onde acredita que terá um bom retorno da produção de teorias sobre o fenômeno estudado. Como nos alerta Hine 10,30, o pesquisador na ambiência digital deve se acostumar com "um sentimento perpétuo de incerteza", sendo convocado a construir interpretações teoricamente sustentadas de eventos que apenas acessa evidência superficial. E não é também assim na pesquisa no "mundo offline"?

\section{Produção e extração de acervo}

Uma das principais características do mundo digital é seu caráter efêmero e volátil, fazendo com que os ambientes por ele produzidos se transformem e se modifiquem de forma acelerada. Assim, faz-se necessário que o pesquisador garanta algum tipo de materialidade ao dado extraído desses ambientes. Se no mundo digital os dados estão na "nuvem", ou seja, em local de hospedagem que é propriedade de uma empresa que disponibiliza este espaço por meio de um cadastro pessoal e criação de uma conta, é fundamental que o pesquisador crie um local de armazenamento que não dependa de acesso à Internet, um ambiente digital ou analógico onde ele possa acessar de forma offline independentemente da plataforma que foi extraído.

Além de evitar problemas operacionais com o acesso à Internet, a criação de um acervo pessoal offline impede ainda que o material de pesquisa "desapareça" por ter sido retirado da Internet. Tendo em vista que o campo da saúde trata de diversos temas que transitam na fronteira legal/ilegal, as chances de um material ser repentinamente excluído é muito grande. Como exemplo podemos citar uma pesquisa realizada por nós sobre os desafios online que envolvem riscos a crianças e adolescentes por meio de vídeos hospedados no YouTube, cujos materiais postados são constantemente retirados 
do ar por violar as políticas de privacidade. Esse controle pode ser feito por intermédio de algoritmos ou por denúncia dos próprios usuários.

A volatilidade e a efemeridade dos ambientes digitais da Internet 2.0 também são observadas no que concerne às ferramentas de extração de dados. Um dos exemplos mais paradigmáticos é o caso do aplicativo de extração de dados do Facebook, o Netizz. Quando estava ativo, acessava diretamente o conjunto de rotinas e padrões (em inglês Application Programming Interface - API), estabelecidos pelo Facebook para a utilização de suas funcionalidades 43.

Após a denúncia feita contra o Facebook de que essa plataforma estava vendendo dados confidenciais de milhões de usuários do Facebook (o escândalo Cambridge Analitica), a extração de dados dessa plataforma para fins de pesquisa foi cada vez mais dificultada pela empresa. Apesar de o aplicativo ter auxiliado mais de 300 trabalhos acadêmicos, ele foi retirado do ar. Alguns pesquisadores acreditam que a tendência é que todas as API sejam fechadas e a liberação de dados para a pesquisa se torne cada vez mais mercantilizada. Corre-se o risco de que pesquisas sejam cada vez mais limitadas com a alegação da violação de lei de privacidade.

Partindo dessa constatação podemos supor que essa restrição pode conduzir a um caráter mais artesanal da pesquisa. Por exemplo, se o pesquisador tiver a necessidade de saber qual foi a publicação mais curtida em um grupo de mulheres com câncer de mama, terá de consultar cada postagem dentro de um determinado período de tempo e fazer um ranking com base nas variáveis escolhidas para a pesquisa. Assim, colar o conteúdo da rede social no Word, criar tabelas no Excel para contabilizar as curtidas de uma determinada postagem, transportar todo acervo para um software de processamento de dados qualitativos, ou ainda, realizar uma busca manual pelas imagens de um determinado grupo, são tarefas que vão inteiramente na contramão da temporalidade contemporânea da Internet 2.0 e da quantidade de dados a processar. Todavia, certamente novas ferramentas serão construídas e ofertadas a determinado valor de mercado ou, numa perspectiva otimista, serão consideradas ferramentas estratégicas para o desenvolvimento do conhecimento e ofertadas em modo de acesso livre.

Outro aspecto a ser explorado é a possibilidade de coprodução de acervos com os sujeitos de pesquisa. A pesquisa digital permite muito além de "fazer entrevistas" online. Sujeitos da pesquisa podem ser (e muitos já são) produtores e editores de conteúdos em formatos diversos (fotos, textos, vídeos, imagens). O pesquisador pode pedir que os sujeitos produzam conteúdos, falando de suas experiências, pontos de vista, ideias e discutir os sentidos que lhes são atribuídos 7,44.

Outro efeito da cultura da conectividade digital, expressa nas interações das redes sociais, que pode ser uma armadilha para o pesquisador inexperiente é se deparar com uma quantidade incomensurável de material (milhares de textos, emojis, emoticons, comentários, vídeos, gifs, fotos etc.). Raramente será possível fazer uma etnografia ou uma análise em profundidade querendo abarcar todas as manifestações que ali se apresentam. Assim, é preciso definir eixo de relações, dimensões e focos num conjunto quase infinito de materiais empíricos 7,45.

Por fim, vale lembrar que a pandemia e suas restrições sanitárias têm levado a um hiperuso da Internet 27 , elementos que podem ajudar a desmitificar as formas de comunicação digital para um maior número de usuários (especialmente os não nativos digitais), por outro lado, o uso excessivo dessas mídias pode levar a um certo nível de "impaciência" com abordagens de pesquisa.

\section{Conclusões}

O contexto da pandemia da COVID-19 nos convoca a adaptar nossos estudos, migrando para as ambiências da pesquisa digital. Todavia, à medida em que as interações humanas são cada vez mais mediadas pela Internet, a pesquisa em ambiência online constitui uma exigência heurística que ultrapassa as soluções estratégicas emergenciais geradas pelas contingências sanitárias de distanciamento social. Isso convoca e desafia todos os pesquisadores a compreender melhor "o mundo digital", ampliando horizontes para além do entendimento reduzido de um "lugar" onde será fácil recolher muitos dados e fazer entrevistas online.

Esse "mundo digital" ainda que seja estruturado por algoritmos em ação nas diversas plataformas se efetiva por linguagens próprias, forja comportamentos e dinâmicas interacionais que ganham sentido à luz de seus contextos técnico-socioculturais A concepção de campo-fluxo-rede nos desafia 
a percorrer juntos com os participantes de pesquisa os caminhos de sua volatilidade e mobilidade, desvendando interpretativamente seus diferentes usos culturais e performances em cada ambiência digital.

A pesquisa nas ambiências digitais descortina um campo exponencial de possibilidades, seja de explorar as formas que essa socialidade assume em nossos cotidianos, como modula nossas (inter) subjetividades, como permite a produção de narrativas e performances identitárias, associações para propósitos diversos, entre tantas outras possibilidades. Oferece ainda generosamente acervos sobre quase todas as práticas sociais imaginadas. Nos exige, portanto, o corajoso exercício da criatividade, intuição e espontaneidade - qualidades que se aliam ao rigor teórico, à clareza conceitual e ao respeito ético às alteridades.

\section{Colaboradores}

Os autores colaboraram igualmente na proposição, elaboração e revisão do texto.

\section{Informações adicionais}

ORCID: Suely Deslandes (0000-0002-7062-3604); Tiago Coutinho (0000-0002-0545-9457).

\section{Agradecimentos}

Ao apoio do Conselho Nacional de Desenvolvimento Científico e Tecnológico (CNPq; financiamento 409048/2018-6).

\section{Referências}

1. Denzin N, Lincoln Y. The discipline and practice of qualitative research. In: Denzin NK, Lincoln YS, editors. Handbook of qualitative research. 2nd Ed. Thousand Oaks: Sage; 2000. p. 1-32.

2. Miller D. Como conduzir uma etnografia durante o isolamento social. https://www.you tube.com/watch?v=WC24b3nzp98 (acessado em 25/Mai/2020).

3. Kluge H. Statement to the press by Dr Hans Henri P. Kluge, WHO Regional Director for Europe. Geneva: World Health Organization; 2020

4. World Health Organization. Coronavirus disease 2020 (COVID-19). Geneva: World Health Organization; 2020. (Situation Report, 67).

5. Pink S, Hjorth L, Horst HA. Digital ethnography: principles and practice. Los Angeles: Sage; 2016.

6. Hine C. Internet research and the sociology of cyber-social-scientific knowledge. Information Society 2005; 21:239-48.

7. Rogers R. Digital methods. Cambridge: The MIT Press; 2013.

8. Lupton D. Digital sociology. Abingdon: Routledge, Taylor \& Francis Group; 2015.

9. Daniels J, Gregory K, Cottom TM. Digital sociologies. London: Policy Press; 2017.

10. Hine C. Virtual ethnography. London: Sage; 2000.

11. Horst HA, Miller D. Digital anthropology. London/New York: Berg; 2012.

12. Frossard VC, Dias MCMO. Impacto da internet na interação entre pacientes: novos cenários em saúde. Interface Comun Saúde Educ 2016; 20:349-61.

3. Coutinho T, Esher AF, Osorio-de-Castro CGS. Mapeando espaços virtuais de informação sobre TDA/H e usos do metilfenidato. Physis (Rio J.) 2017; 27:749-69. 
14. Vasconcellos-Silva PR, Castiel L, Bagrichevsky M, Griep RH. As novas tecnologias da informação e o consumismo em saúde. Cad Saúde Pública 2010; 26:1473-82.

15. Paolucci R, Pereira Neto A, Luzia R. Avaliação da qualidade da informação em sites de tuberculose: análise de uma experiência participativa. Saúde Debate 2017; 41(n.spe):84-100.

16. Syred J, Naidoo C, Woodhall SC, Baraitser P. Would you tell everyone this? Facebook conversations as health promotion interventions. J Med Internet Res 2014; 16:e108.

17. Strathern M, Peel J, Toren C, Spencer J, Ingold T. The concept of society is theoretically obsolete. In: Ingold T, editor. Key debates in anthropology. London: Routledge; 1996. p. 50-5.

18. Maffesoli M. O tempo das tribos: o declínio do individualismo nas sociedades de massa. Rio de Janeiro: Forense Universitária; 2014.

19. van Dijck J. La cultura de la conectividad: una historia crítica de las redes sociales. Buenos Aires: Siglo Veinteuno; 2016.

20. Roesler R. Web 2.0, interações sociais e construção do conhecimento. https://www.aedb. br/wp-content/uploads/2015/04/45817495. pdf (acessado em 25/Mai/2020).

21. Sibilia P. O show do eu: a intimidade como espetáculo. Rio de Janeiro: Nova Fronteira; 2008.

22. Miller D, Slater D. The internet: an ethnographic approach. New York: Berg; 2001.

23. Miller $\mathrm{H}$. The presentation of self in electronic life: Goffman on the internet. http://www. douri.sh/classes/ics234cw04/miller2.pdf (acessado em 25/Mai/2020).

24. Ferreira GB. "Como me verão os outros?" Sobre o Facebook e a construção da identidade online. Estudos em Comunicação 2014; (17):21-46.

25. Bruno F. Máquinas de ver, modos de ser: vigilância, tecnologia e subjetividade. Porto Alegre: Sulina; 2013.

26. Silveira SA. Governo dos algoritmos. Revista de Políticas Públicas 2017; 21:267-81.

27. Deslandes SF, Coutinho T. O uso intensivo da internet por crianças e adolescentes no contexto da COVID-19 e os riscos para violências autoinflingidas. Ciênc Saúde Colet 2020; 25 Suppl 1:2479-86.

28. Gomes LG. Avatares: o maravilhoso e o estranho no second life. Estudos Históricos 2020; 33:173-95.

29. Lévy P. O que é o virtual? 2a Ed. São Paulo: Editora 34; 2011.

30. Hine C. Ethnography for the Internet: embedded, embodied and everyday. London: Bloomsbury Academic; 2015.
31. Law J. Notes on the Theory of the Actor-Network: ordering, strategy and heterogeneity. Systems Practice 1992; 5:379-93.

32. Malinowski B. Objeto: método e alcance desta pesquisa. In: Guimarães AZ, organizador. Desvendando máscaras sociais. 2a Ed. Rio de Janeiro: Francisco Alves; 1980. p. 39-61.

33. Mauss M. Sociologia e antropologia. São Paulo: Cosac \& Naify; 2003.

34. Madianou M, Miller D. Polymedia: towards a new theory of digital media in interpersonal communication. International Journal of Cultural Studies 2013; 16:169-87.

35. Bakhtin M. Os gêneros do discurso. São Paulo: Editora 34; 2016.

36. Maingueneau D. Gêneros do discurso e web: existem os gêneros web? Revista da ABRALIN 2017; 15:135-60.

37. Hammersley M, Atkinson P. Ethnography: principles in practice. 2nd Ed. London: Routledge; 1995.

38. Brancaleone C. Comunidade, sociedade e sociabilidade: revisitando Ferdinand Tönnies. Revista de Ciências Sociais 2008; 39:98-104.

39. Recuero R. Redes sociais na Internet. Porto Alegre: Sulina; 2011.

40. Marcus G. Ethnography in/of the world system: the emergence of multi-sited ethnography. Annu Rev Anthropol 1995; 24:95-117.

41. Markham A. Ethnography in the Digital Internet Era: from Fields to Flows, descriptions to interventions. In: Denzin NK, Lincoln YS, editors. The SAGE handbook of qualitative research. 5th Ed. New York: Sage Publications; 2018. p. 1121-53.

42. Geertz C. A interpretação das culturas. Rio de Janeiro: LTC; 2008.

43. Rieder B. Studying Facebook via data extraction: the Netvizz application. In: 5th Annual ACM Web Science Conference. Paris: Association for Computing Machinery; 2013. p. 34655.

44. Vasconcellos MS, Araújo IS. Usos da etnografia em mundos virtuais baseados na imagem. RECIIS 2011; 5:75-85.

45. Noveli M. Do off-line para o on-line: a netnografia como um método de pesquisa ou o que pode acontecer quando tentamos levar a etnografia para a internet? Revista Organizações em Contexto 2010; 6:107-33. 
Abstract

The COVID-19 pandemic and the sanitary measures of social distance brought impasses to Social Research and its future. Research in digital environments was already booming, but now that faceto-face activities are temporarily suspended, it becomes an alternative to enable the continuity of studies. Understanding it better is an epistemological and methodological need for all researchers. Thus, the objective of this essay is to propose some theoretical and methodological considerations on qualitative research in the different digital environments formed by the Internet 2.0. We point out some introductory aspects and tensions considered strategic for those who are going to start their work in social networks supported by the Internet. We organized the article based on the following topics: (1) digital sociality; (2) the "digital environment" and the blurring of boundaries between real-virtual; (3) the redefinition of the meaning of "field" in the digital environment; (4) the different cultural uses of digital platforms; (5) platforms as producers of discursive genres; (6) the production and extraction of collections. The essay seeks to demonstrate that research in digital environments reveals an exponential field of possibilities, whether to explore the forms that this sociality assumes in our daily lives, or to modulate our (inter) subjectivities, as it allows the production of identity narratives and performances, associations for different purposes, among many other possibilities. However, it demands an understanding of social action based on the synergy of the socio-technicalcultural contexts that structure it.

COVID-19; Internet; Social Media; Qualitative Research; Methodology

\section{Resumen}

La pandemia de COVID-19 y las medidas sanitarias de distanciamiento social trajeron impases para la Investigación Social y su futuro. La investigación en ambientes digitales ya estaba en franca expansión, pero en este momento de suspensión de actividades presenciales se convierte en una alternativa para viabilizar la continuidad de los estudios. Comprenderla mejor se convierte en una necesidad epistemológica y metodológica para todos los investigadores. Por ello, el objetivo de este trabajo es proponer algunas consideraciones teórico-metodológicas sobre la investigación cualitativa en los diferentes ambientes digitales formados por la Internet 2.0. Puntuamos algunos aspectos y tensiones introductorias que consideramos estratégicas para los que van a comenzar su trabajo en las redes de sociabilidad sostenidas por la Internet. Organizamos el artículo a partir de los siguientes temas: 1. La sociabilidad digital; 2. El "ambiente digital" y la desaparición de fronteras entre lo real-virtual; 3. La redefinición del significado de "campo" en el entorno digital; 4. Los diferentes usos culturales de las plataformas digitales; 5 . Las plataformas como productoras de géneros discursivos; 6. La producción y extracción de acervos. El trabajo busca demostrar que la investigación en los entornos digitales desvela un campo exponencial de posibilidades, sea para explorar las formas que esa sociabilidad asume en nuestros cotidianos, sea para modular nuestras (inter)subjetividades, al permitir la producción de narraciones y performances identitarias, asociaciones para propósitos diversos, entre tantas otras posibilidades. Asimismo, demanda una comprensión de la acción social a partir de la sinergia de los contextos socio-técnico-culturales que la estructuran.

COVID-19; Internet; Medios de Comunicación Sociales; Investigación Cualitativa; Metodología

Recebido em 27/Jul/2020

Versão final reapresentada em 12/Ago/2020

Aprovado em 20/Ago/2020 